\section{Efecto antibacteriano in vitro de extractos de Caesalpinia spinosa sobre cepas de Staphylococcus aureus resistentes a antibióticos betalactámicos}

\section{In vitro antimicrobial effect of Caesalpinia spinosa extracts against betalactam antibiotics resistant Staphylococcus aureus strains}

\begin{abstract}
Resumen
Objetivo. Determinar el efecto antimicrobiano de extractos etanólicos de Caesalpinia spinosa sobre cepas de Staphylococcus aureus penicilino y meticilino resistentes. Métodos. Se utilizaron las cepas de $S$. aureus ATCC 11632 y 33592, los extractos etanólicos de hojas, vainas y semillas de $C$. spinosa, se obtuvieron por maceración en concentraciones de $25 \%, 50 \%, 75 \%$ y $100 \%$. Se utilizó el método de Kirby-Bauer, los discos de papel filtro se cargaron con los extractos y se depositaron sobre el medio, inoculado con una suspensión de $S$. aureus a $0,5 \mathrm{McF}$ arland. El control positivo fueron discos de ampicilina y el control negativo discos impregnados con etanol. Después de 24 horas se midieron los diámetros de los halos con un calibrador Vernier. Resultados. Se registraron halos de hasta $18 \mathrm{~mm}$ de diámetro con los extractos de hojas al 100\%, $17 \mathrm{~mm}$ con extractos de vainas y $14 \mathrm{~mm}$ con extractos de semillas sobre $S$. aureus ATCC 33592. En el caso de la cepa ATCC 11632, se registraron halos de hasta $14 \mathrm{~mm}$ con extractos de hojas y vainas al $100 \%$, y de hasta $8 \mathrm{~mm}$ con extractos de semillas. La prueba de ANOVA indicó que existieron diferencias significativas entre los halos obtenidos con los diferentes tipos de extractos, a diferentes concentraciones. Conclusión. Se determinó que todos los extractos de C. spinosa poseen actividad antimicrobiana sobre las dos cepas estudiadas, con un patrón directamente proporcional entre el efecto y la concentración.
\end{abstract}

Palabras clave: Staphylococcus aureus resistente a meticilina; Caesalpinia; Resistencia antibiótica; Antibiograma (fuente: DeCS, BIREME).

\begin{abstract}
Objective. To determine the antimicrobial effect of ethanolic extracts from Caesalpinia spinosa against penicillin and methicillin resistant strains of Staphylococcus aureus penicillin and methicillin. Methods. S. aureus ATCC 11632 and 33592 strains were used, ethanolic extracts from $C$. spinos $a$ leaves and pods were obtained by maceration at concentrations of $25 \%, 50 \%, 75 \%$ and $100 \%$. The Kirby-Bauer method was used, where filter paper discs were loaded with leaf, pod and seed extracts and deposited on the medium, inoculated with a $0.5 \mathrm{McF}$ arland suspension of $S$. aureus. Ampicillin discs were used as positive control and ethanol-impregnated discs as negative control. After 24 hours, the diameters of the halos were measured with a Vernier caliper. Results. Haloes up to $18 \mathrm{~mm}$ in diameter with $100 \%$ leaf extracts, $17 \mathrm{~mm}$ with pod extracts and $14 \mathrm{~mm}$ with seed extracts were
\end{abstract}

\section{Artículo Original}

Bryan Darío Villavicencio Coral ${ }^{1, a}$, Jéssica María Sarmiento Ordóñez ${ }^{1, b}$, Carol Gissel Flores Regalado 2,c, José Esteban Torrachi Carrasco 1,d

1 Universidad Católica de Cuenca, Unidad Académica de Salud y Bienestar, Carrera de Odontología, Cuenca, Ecuador.

${ }^{2}$ Ministerio de Salud Pública del Ecuador, Cuenca,

Ecuador.

a Odontólogo General.

${ }^{\mathrm{b}}$ Magíster en Microbiología.

c Odontóloga General de servicio rural.

${ }^{d}$ Doctor en Manejo y Conservación de Recursos Genéticos.

\section{Correspondencia:}

Jéssica María Sarmiento Ordóñez: jsarmientoo@ucacue. edu.ec

Avenida de las Américas y Tarqui. CP: 010105. Cuenca-

Ecuador.

ORCID: 0000-0001-6603-9758

\section{Coautores:}

Bryan Darío Villavicencio Coral: daryvill@hotmail.es ORCID: 0000-0001-8361-4064

Carol Gissel Flores Regalado: cgfloresr26@est.ucacue. edu.ec

ORCID: 0000-0002-1793-733X

José Esteban Torrachi Carrasco: jtorracchic@ucacue. edu.ec

ORCID: 0000-0002-8901-7022

\section{Editora:}

Dahiana Alfaro Carballido

Universidad de San Martín de Porres, Perú.

Conflicto de intereses: los autores declaran no tener ningún conflicto de interés.

Fuente de financiamiento: el presente estudio fue autofinanciado.

Recibido: $10 / 08 / 20$

Aceptado: 12/02/21

Publicado: 01/07/21 
recorded against $S$. aureus ATCC 33592; for ATCC strain 11632, haloes up to $14 \mathrm{~mm}$ with $100 \%$ leaf and pod extracts and up to $8 \mathrm{~mm}$ with seed extracts were recorded. The ANOVA test indicated significant differences between the inhibition halos obtained with the different types of extracts, at different concentrations. Conclusion. It was determined that all $C$. spinosa extracts possess antimicrobial activity against the two strains studied, with a pattern directly proportional between the effect and concentration.

Keywords: Methicillin-resistant Staphylococcus aureus; Caesalpinia; Antibiotic resistance; Antibiogram (source: MeSH NLM).

\section{Introducción}

Los antibióticos constituyen la primera elección para la terapia de infecciones de origen bacteriano, mejorando los resultados clínicos y reduciendo la morbilidad y mortalidad causadas por este tipo de infecciones. Sin embargo, su uso indiscriminado y poco controlado también puede promover la aparición de cepas bacterianas resistentes e incluso multirresistentes, siendo este un problema de salud pública de repercusión mundial ${ }^{1-4}$. De hecho, en el 2013, se reportaron 9,2 millones de muertes por infección bacteriana, es decir el $17 \%$ del total de muertes, muchas de las cuales se debieron a cepas resistentes ${ }^{1,2}$. Frente a esta emergencia, se ha insistido en la necesidad de desarrollar nuevos métodos para tratar las infecciones, que incluyan el descubrimiento o síntesis de nuevos antimicrobianos como alternativas de tratamiento ${ }^{2}$. Entre estas posibilidades se ha reportado que los fitoquímicos, obtenidos a partir de fuentes naturales como las plantas autóctonas de cultivo ancestral han demostrado tener una potente actividad antimicrobiana, comparable a la de los antibióticos, ante diferentes especies microbianas e incluso hongos, sin originar resistencia ${ }^{2,3}$. Estos compuestos vegetales pueden actuar solos o en combinación con antibióticos para mejorar su actividad antimicrobiana, y son efectivos contra una amplia variedad de bacterias ${ }^{1,2}$. El 75\% de la población mundial utiliza plantas con fines terapéuticos y preventivos ${ }^{5}$. Dos tercios de los químicos identificados cada año provienen de plantas 5. Actualmente, muchas de estas plantas o sus componentes con actividad antimicrobiana se encuentran disponibles comercialmente ${ }^{1-3,5}$.

C. spinosa ("tara", "guarango" o "taya") es una leguminosa arbustiva, originaria de países de la región andina 6,7. En Ecuador, crece en varias zonas de la sierra. Esta planta es utilizada en las industrias, alimenticia, farmacéutica, entre otras, por el hecho de que sus frutos y semillas presentan propiedades medicinales y alimenticias, dado que ha sido aprobada por la OMS y la FAO (Organización mundial de la Salud y Organización para la Alimentación y Agricultura, respectivamente) como segura para su consumo. Por otro lado, se ha reportado su uso como agente terapéutico, debido a sus propiedades antihemorrágicas, analgésicas, y antiinflamatorias ${ }^{6,7}$. Se ha comprobado que los taninos, compuestos fenólicos, flavonoides y péptidos de C. spinosa tienen un efecto antibacteriano in vitro similar a los de antibióticos de amplio espectro ${ }^{6-8}$. Por otro lado, los extractos alcohólicos tienen efecto inhibitorio sobre el crecimiento de cepas bucales como: Streptococcus mutans, Streptococcus salivarius, Lactobacillus casei, Streptococcus oralis, en experimentos realizados in vitro ${ }^{6}$.

Staphylococcus aureus es una especie bacteriana que se encuentra con frecuencia en la cavidad nasofaríngea, pero puede llegar a la cavidad bucal y es responsable de infecciones bucodentales tales como la parotiditis, la queilitis angular, la periimplantitis, y la periodontitis, empeorando además su pronóstico ${ }^{9-12}$. Entre sus múltiples factores de virulencia, destaca la resistencia a antibióticos (betalactámicos, macrólidos, entre otros), la cual puede ser adquirida por transmisión horizontal de genes ${ }^{9,10,13}$. La ocurrencia de cepas de $S$. aureus resistentes a antibióticos ha aumentado en los últimos años; se reporta que es mayor la prevalencia de cepas adquiridas en medio comunitario ( $>56 \%$ de las especies resistentes) que en medio hospitalario ${ }^{10,13,14}$.

Los estudios relacionados con el efecto inhibitorio de extractos de C. spinosa sobre cepas bacterianas resistentes son escasos, especialmente en Ecuador. Es por ello que se requiere de estudios actualizados que amplíen la información disponible sobre la actividad antimicrobiana que posee esta especie vegetal sobre diferentes especies de bacterias. Por tal razón, el objetivo del presente estudio fue determinar el efecto in vitro de extractos etanólicos de C. spinosa sobre cepas resistentes de $S$. aureus.

\section{Métodos}

El presente estudio fue de tipo experimental in vitro. En el mismo se evaluó la actividad antibacteriana in vitro de extractos etanólicos de C. spinosa sobre las cepas de colección $S$. aureus ATCC 11632(penicilino-resistente) y S. aureus ATCC 33592 (gentamicina, meticilino-resistente).

Preparación de los extractos. Primero se lavaron las muestras con abundante agua destilada; posteriormente se secaron a temperatura ambiente durante 7 días y en una estufa a $38^{\circ} \mathrm{C}$ por 48 horas ${ }^{15-17}$. Luego se separaron las semillas de las vainas, ambos componentes además de las hojas fueron trituradas en una licuadora por separado. Los productos triturados fueron almacenados en envases de vidrio diferentes, al abrigo de la luz; para la maceración, se utilizó etanol al 96\% en todas las muestras ${ }^{18-20}$ Las cantidades de etanol se determinaron según el peso, de esta manera, se colocó $750 \mathrm{ml}$ de etanol en $100 \mathrm{~g}$ de muestra de hojas, $1100 \mathrm{ml}$ de etanol en 600 g de muestra de vainas y $900 \mathrm{ml}$ de etanol en $600 \mathrm{~g}$ de muestra de semillas. Posteriormente fueron almacenados en un lugar oscuro y agitados cada 12 horas durante 
4 días ${ }^{18-25}$. Para el filtrado se utilizó el papel filtro tipo Whatman No 1 y 2 y los extractos fueron almacenados a $4^{\circ} \mathrm{C}$ hasta su empleo. El extracto de las hojas fue sometido a tres maceraciones adicionales, mientras que las vainas y las semillas a dos maceraciones, empleando las mismas condiciones antes mencionadas. Posteriormente se procedió a evaporar el etanol de los extractos para lo cual se calentó cada uno de los extractos contenidos en un frasco sobre baño maría a $35^{\circ} \mathrm{C}$ para acelerar la evaporación ${ }^{18,26}$. Luego de ello se desecaron los extractos con silica gel, durante 7 días hasta alcanzar peso constante ${ }^{27}$, con lo cual se obtuvo: 36 gramos de extracto seco de hojas, 144 gramos de extracto seco de vainas y 20 gramos de extracto seco de semillas ${ }^{19,23,24}$.

Diluciones. Se realizaron las diluciones de los extractos con etanol al 96\%, hasta obtener concentraciones de: $100 \%, 75 \%, 50 \%$ y $25 \%$ p/vol, conseguida del principio químico de porcentaje peso a volumen ${ }^{26}$. Y fueron almacenados a $4^{\circ} \mathrm{C}$ hasta su empleo ${ }^{16,24,25}$. Las preparaciones de la concentración de los extractos fueron obtenidas de acuerdo a lo indicado en la tabla 1 .

Prueba de difusión en agar Kirby-Bauer. Se prepararon y esterilizaron los discos de papel filtro Whatman. Luego fueron cargados con los diferentes tipos de extractos: $24 \mu \mathrm{l}$ de extracto de hojas, $24 \mu \mathrm{l}$ de extracto de vainas y $100 \mu \mathrm{l}$ de extracto de semillas, volúmenes que permitieron depositar $12 \mathrm{mg}$ de extracto al $100 \%, 9 \mathrm{mg}$ al $75 \%, 6 \mathrm{mg}$ al $50 \%$ y $3 \mathrm{mg}$ al $25 \%$ en cada uno de estos discos, todos los discos fueron trabajados en una cabina de flujo laminar para permitir la evaporación total del solvente. Se colocó más volumen de extracto en el disco de semillas debido a que el extracto no fue lo suficientemente concentrado como los otros. En total se depositaron seis discos en cada caja petri con agar Müller Hinton, cuatro discos de los extractos $(100 \%$, $75 \%, 50 \%$ y $25 \%$ ), el control positivo y el control negativo ${ }^{19-30}$. Cada extracto se trabajó por cuadriplicado $20,22,31,32$. El control positivo fue el disco comercial de Ampicilina Bioanalyse $e^{\oplus}$ de $10 \mu \mathrm{g}$ el control negativo fue etanol al 96\% ${ }^{18,33,34}$. Las pruebas antimicrobianas se realizaron mediante el método de difusión de disco en agar de Kirby-Bauer ajustando a 0,5 McFarland la dilución bacteriana con solución salina, se realizó cada prueba de los extractos por cuadruplicado, considerando los criterios del Clinical and Laboratory Standards Institute CLSI (USA). ${ }^{15,16,18,19,21,32}$. Una vez finalizado el período de incubación se midieron los diámetros de los halos de inhibición formados alrededor de los discos con la ayuda de un calibrador Vernier ${ }^{18}$. Y el cálculo del porcentaje del efecto inhibitorio relativo, respecto al control positivo, se procedió a realizar aplicando la siguiente fórmula ${ }^{18,19,21,30}$.

$\%$ Efecto inhibitorio $=\frac{\text { media de diámetro del halo de inhibición }}{\text { diámetro de halo de inhibición control positivo }} \times 100$

Aspectos bioéticos. La presente investigación se llevó a cabo bajo la aprobación previa por parte del Comité de Ética en Investigación de Seres Humanos (CEISH) de la Universidad Católica de Cuenca. Debido a que no requirió de procedimientos en los que participen seres humanos y animales, se considera que no implicó ningún conflicto bioético; además de que se siguieron todos los protocolos y normas de bioseguridad tanto para los investigadores como para el medio ambiente.

Análisis estadístico. Se utilizó el programa estadístico RStudio versión $2.15^{15}$. Se calcularon las medias de cada muestra y su respectiva desviación estándar. Los valores obtenidos fueron sometidos a análisis de varianza ANOVA de dos vías, para determinar si existen diferencias significativas entre extractos y entre concentraciones trabajando con una significancia de $\mathrm{p} \leq 0,05$ y un nivel de confiabilidad de $95 \%$.

\section{Resultados}

Todos los extractos etanólicos de C. spinosa evaluados presentaron acción inhibitoria frente a ambas cepas ( $\mathrm{Ta}-$ bla 2). Se observa igualmente que la acción inhibitoria es directamente proporcional a la concentración del extracto (Tabla 2 y 3). Al analizar en grupo todas las concentraciones de los diferentes tipos de extractos sobre las dos cepas de $S$. aureus, se presentaron diferencias significativas ( $\mathrm{p}<0,001$ con ANOVA) (Tabla 4).

La concentración que menor efecto presentó fue la de $25 \%$ sobre $S$. aureus ATCC 11632 y S. aureus ATCC 33592. La mayor concentración al 100\% fue la que mayor efecto presentó con todos los extractos, existiendo diferencias significativas $(\mathrm{p}<0,001)$ (Tablas 3 y 4 ).

Los extractos con concentraciones al 50 y al $75 \%$ presentaron diferencias significativas $(\mathrm{p}<0,001$ en ambos) (Tabla 4).

Existen diferencias significativas al comparar los tipos de extractos $(\mathrm{p}<0,001)$ (Tabla 4). En base a los diámetros de los halos inhibitorios, el efecto antibacteriano del extracto de hojas es mayor al de vainas y semillas, y el efecto de los extractos de vainas es superior al efecto de los extractos de semillas (Tabla 3).

Tabla 1. Preparación de la concentración de los extractos por hoja, vaina y semilla

\begin{tabular}{|c|c|c|c|}
\hline \multirow{2}{*}{$\begin{array}{l}\text { Concentración } \\
\text { de los extractos }\end{array}$} & Hojas & Vainas & Semillas \\
\hline & $\mathrm{p} / \mathrm{vol}$ & $\mathrm{p} / \mathrm{vol}$ & $\mathrm{p} / \mathrm{vol}$ \\
\hline $100 \%$ & $12 \mathrm{mg} / 24 \mu \mathrm{l} \mathrm{EC}$ & $12 \mathrm{mg} / 24 \mu \mathrm{l} \mathrm{EC}$ & $12 \mathrm{mg} / 24 \mu \mathrm{l} \mathrm{EC}$ \\
\hline $75 \%$ & $9 \mathrm{mg} / 18 \mu \mathrm{l} \mathrm{EC}+6 \mu \mathrm{l}$ etanol $96 \%$ & $9 \mathrm{mg} / 18 \mu \mathrm{l} \mathrm{EC}+6 \mu \mathrm{l}$ etanol $96 \%$ & $9 \mathrm{mg} / 75 \mu \mathrm{l} \mathrm{EC}+25 \mu \mathrm{l}$ etanol 96\% \\
\hline $50 \%$ & $6 \mathrm{mg} / 12 \mu \mathrm{l} \mathrm{EC}+12 \mu \mathrm{l}$ etanol $96 \%$ & $6 \mathrm{mg} / 12 \mu \mathrm{l} \mathrm{EC}+12 \mu \mathrm{l}$ etanol $96 \%$ & $6 \mathrm{mg} / 50 \mu \mathrm{l} \mathrm{EC}+50 \mu \mathrm{l}$ etanol $96 \%$ \\
\hline $25 \%$ & $3 \mathrm{mg} / 6 \mu \mathrm{l} \mathrm{EC}+18 \mu \mathrm{l}$ etanol $96 \%$ & $3 \mathrm{mg} / 6 \mu \mathrm{l} \mathrm{EC}+18 \mu \mathrm{l}$ etanol 96\% & $3 \mathrm{mg} / 25 \mu \mathrm{l} \mathrm{EC}+75 \mu \mathrm{l}$ etanol $96 \%$ \\
\hline
\end{tabular}


Tabla 2. Porcentaje del efecto inhibitorio

\begin{tabular}{cccc}
\hline \multicolumn{2}{c}{ ATCC11632 } & \multicolumn{2}{c}{ ATCC 33592 } \\
\hline Extracto & \% de efecto inhibitorio & Extracto2 & \% de efecto inhibitorio \\
\hline Hojas & & Hojas & 318,18 \\
\hline $100 \%$ & 87,30 & $100 \%$ & 263,63 \\
$75 \%$ & 74,6 & $75 \%$ & 213,63 \\
$50 \%$ & 65,1 & $50 \%$ & 136,36 \\
$25 \%$ & 49,2 & $25 \%$ & 366,66 \\
\hline Vainas & & Vainas & 305,55 \\
$100 \%$ & 94,8 & $100 \%$ & 250 \\
$75 \%$ & 67,2 & $75 \%$ & 144,44 \\
$50 \%$ & 37,9 & $50 \%$ & 286,66 \\
$25 \%$ & 11,4 & $25 \%$ & 233,33 \\
\hline Semillas & & Semillas & 180 \\
\hline $100 \%$ & 51,7 & $100 \%$ & 113,33 \\
\hline $75 \%$ & 39,6 & $75 \%$ & $50 \%$ \\
\hline
\end{tabular}

\%: Porcentaje

Tabla 3. Datos descriptivos de la medida del diámetro del halo en $\mathrm{mm}$ de los extractos etanólicos de $C$. spinosa

\begin{tabular}{|c|c|c|c|c|c|}
\hline \multicolumn{2}{|c|}{ Extracto } & \multicolumn{2}{|c|}{ S. aureus ATCC 11632} & \multicolumn{2}{|c|}{ S. aureus ATCC 33592} \\
\hline & Conc. & Media & DE & Media & DE \\
\hline \multirow[t]{4}{*}{ Hojas } & $100 \%$ & 13,75 & $\pm 0,50$ & 17,50 & $\pm 0,58$ \\
\hline & $75 \%$ & 11,75 & $\pm 0,50$ & 14,50 & $\pm 0,58$ \\
\hline & $50 \%$ & 10,25 & $\pm 0,50$ & 11,75 & $\pm 0,96$ \\
\hline & $25 \%$ & 7,75 & $\pm 0,50$ & 7,50 & $\pm 0,58$ \\
\hline $\mathrm{CP}$ & & 15,75 & $\pm 0,50$ & 5,5 & $\pm 0,58$ \\
\hline \multirow[t]{4}{*}{ Vainas } & $100 \%$ & 13,75 & $\pm 0,50$ & 16,50 & $\pm 1,0$ \\
\hline & $75 \%$ & 9,75 & $\pm 0,50$ & 13,75 & $\pm 1,26$ \\
\hline & $50 \%$ & 5,50 & $\pm 0,58$ & 11,75 & $\pm 1,26$ \\
\hline & $25 \%$ & 1,75 & $\pm 0,50$ & 6,75 & $\pm 1,26$ \\
\hline $\mathrm{CP}$ & & 14,5 & \pm 0.58 & 4,5 & $\pm 0,58$ \\
\hline \multirow[t]{4}{*}{ Semillas } & $100 \%$ & 7,50 & $\pm 0,58$ & 10,75 & $\pm 2,22$ \\
\hline & $75 \%$ & 5,75 & $\pm 0,50$ & 8,75 & $\pm 2,22$ \\
\hline & $50 \%$ & 2,75 & $\pm 0,50$ & 6,75 & $\pm 2,22$ \\
\hline & $25 \%$ & 1,00 & $\pm 0,0$ & 4,25 & $\pm 1,89$ \\
\hline $\mathrm{CP}$ & & 14,5 & $\pm 0,58$ & 3,75 & $\pm 0,98$ \\
\hline
\end{tabular}

Conc: Concentración del extracto

DE: Desviación estándar

CP: Control positivo

Tabla 4. Comparación de medias entre los diferentes extractos ensayados

\begin{tabular}{ccccc}
\hline & Valor Estimado & Error estándar & Valor $\mathbf{t}$ & $\mathbf{P}$ \\
\hline Intercepción & 10,7396 & 0,7317 & 14,677 & $<0,001$ \\
Tipo de extracto & $-2,9531$ & 0,2834 & $-10,421$ & $<0,001$ \\
Concentración del extracto 50\% & 3,2917 & 0,6545 & 5,030 & $<0,001$ \\
Concentración del extracto 75\% & 5,8750 & 0,6545 & 8,977 & $<0,001$ \\
Concentración del extracto 100\% & 8,4583 & 0,6545 & 12,924 & $<0,001$ \\
\hline
\end{tabular}

Intercepción: Medida del halo en mm - Concentración + tipo de extracto 
El mayor efecto inhibitorio se observó con los extractos de vainas al $100 \%$ en ambas cepas, seguidas de hojas al $100 \%$, mientras que el menor efecto se observó con todos los extractos al $25 \%$, siendo el menor de todos el de semillas al 25\% sobre S. aureus ATCC 11632 (Tabla 2).

Con los extractos de C. spinosa sobre S. aureus 11632 se observó que los extractos de hojas en su menor concentración (25\%) tienen efecto similar al extracto con mayor concentración de las semillas (100\%). Los extractos de hojas al 25\% tienen efecto mayor al de extractos de vainas al $50 \%$ y al $25 \%$ (Tabla 2 ).

Con los extractos de C. spinosa sobre S. aureus 33592 se observó que todos los extractos de vainas demostraron mayor efecto inhibitorio que los extractos de hojas a diferentes concentraciones respectivamente (Tabla 2).

Los extractos de hojas al 75\% tienen mayor efecto inhibitorio que los extractos de semillas al 75\%, 50\% y $25 \%$ (Tabla 2).
Los extractos de hojas tuvieron mayor efecto que los de semillas a las diferentes concentraciones respectivamente (Tabla 2).

Al evaluar el efecto inhibitorio de extractos de C. spinosa sobre $S$. aureus 33592, observamos que el de los extractos de hojas al $100 \%$ es tres veces mayor con respecto al control, mientras que al $75 \%$ y al $50 \%$ es dos veces mayor. Con los extractos de vainas al $100 \%$ el efecto es 3,6 veces mayor, al $75 \% 3,1$ y con el de $50 \%$ es 2,5 veces mayor. Mientras que con los extractos de semillas al $100 \%$ es 2,8 veces mayor y al $75 \% 2,3$ veces mayor al control (Tabla 2).

Se puede observar la formación de los halos inhibitorios de C. spinosa sobre S. aureus 33592 (Figura 1A, 1B y 2B) y sobre $S$. aureus 11632 (Figura 2A).

\section{Discusión}

El objetivo de nuestro estudio fue evaluar la actividad antibacteriana in vitro de extractos etanólicos de hojas,
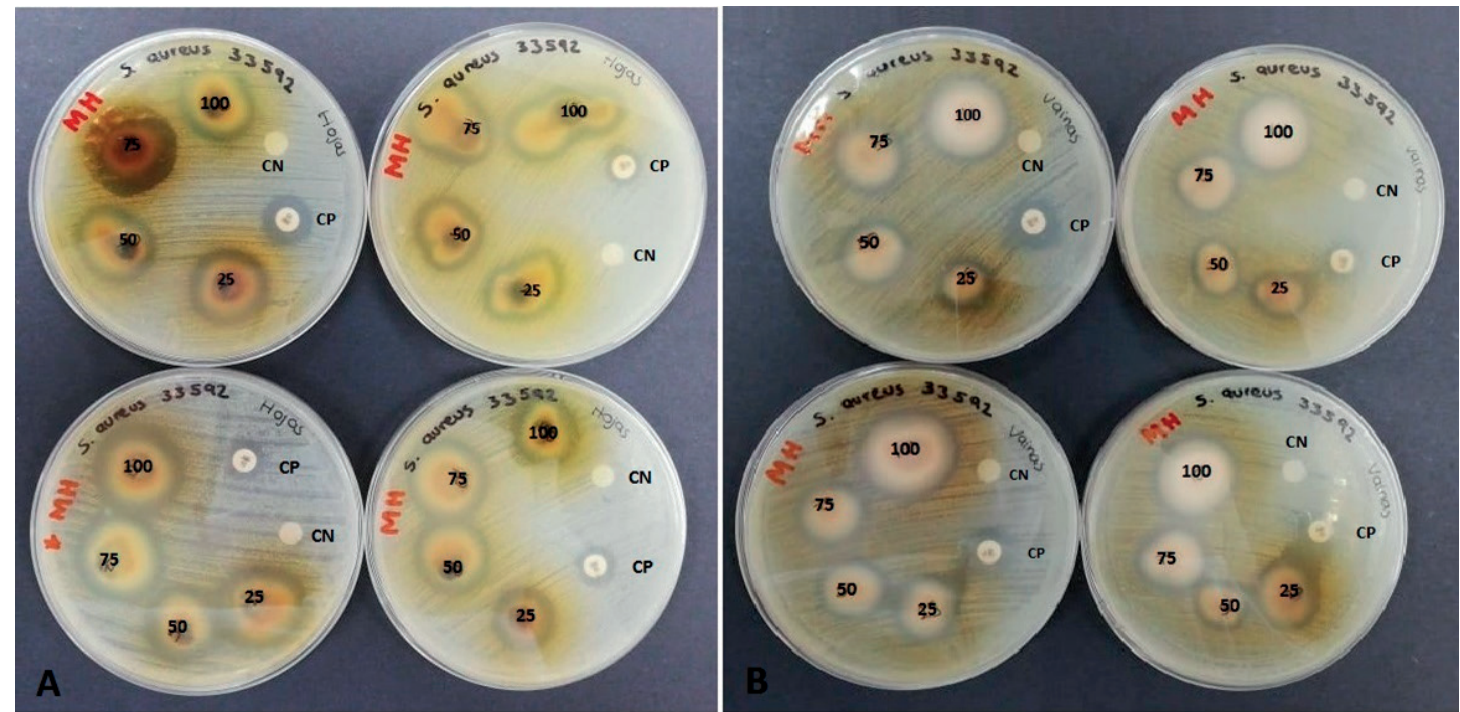

Figura 1. Test de difusión en placa a diferentes concentraciones sobre S. aureus 32592. A. Extractos de hojas B. Extractos de vainas. Control positivo (CP). Control negativo (CN)
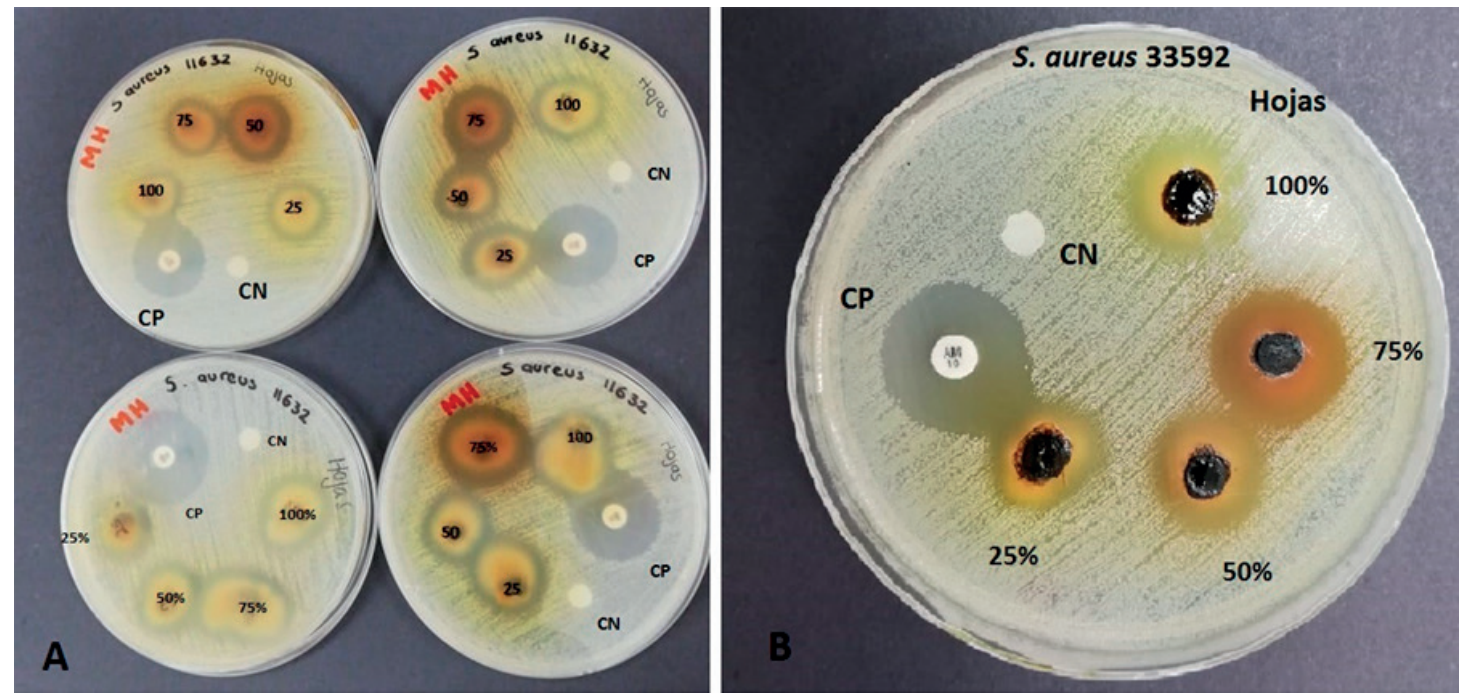

Figura 2. A. Test de difusión en placa de extracto de hojas $C$. spinosa a diferentes concentraciones sobre $S$. aureus 11632. B. Extracto de hojas C. spinosa sobre S. aureus 33592. Control positivo (CP). Control negativo (CN) 


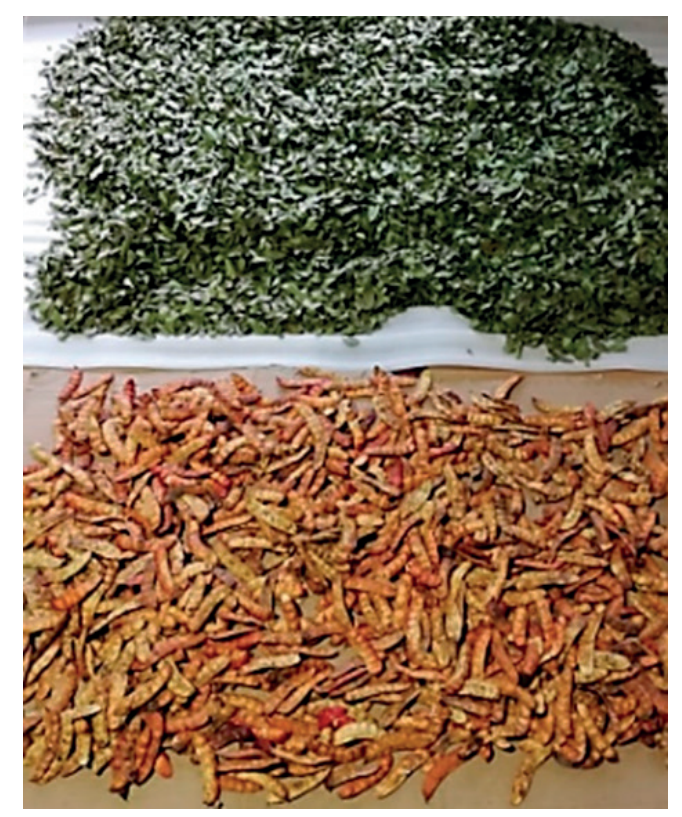

Figura 3. Preparación de la muestra de frutos y hojas de C. Spinosa

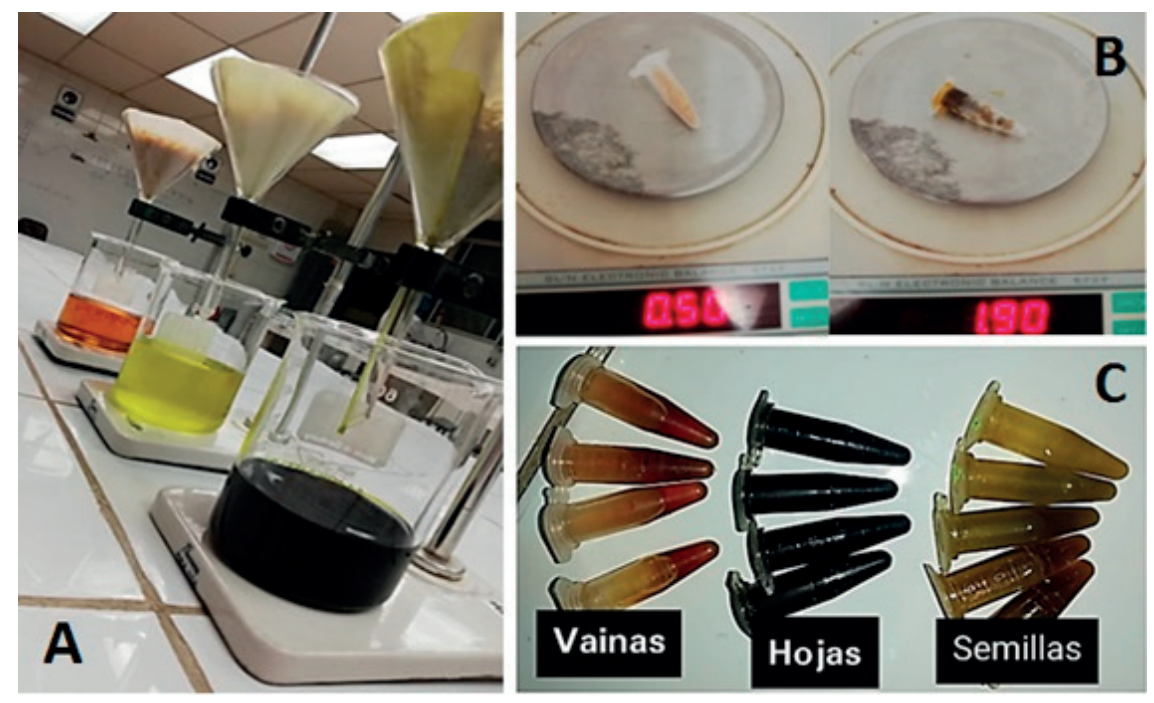

Figura 4. A. Filtrado de los extractos etanólicos. B. Pesaje del producto triturado extractos en seco. C. Extractos etanólicos almacenados en tubos y refrigerados

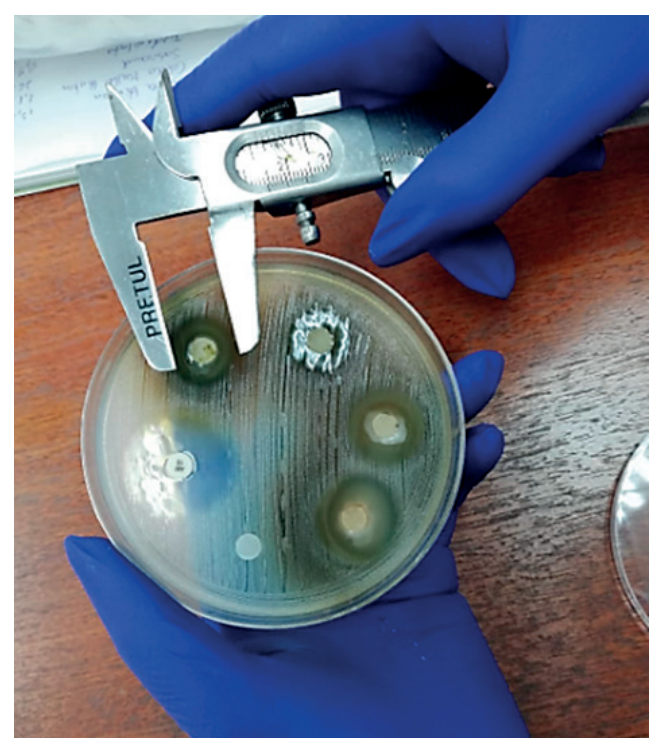

Figura 5. Lectura de halos inhibitorios 
vainas y semillas de Caesalpinia spinosa a diferentes concentraciones sobre cepas resistentes de $S$. aureus mediante test de difusión en disco por el método de Kirby-Bauer. Los resultados obtenidos muestran que todos los extractos evaluados inhibieron el crecimiento de ambas cepas bacterianas. Esto confirma que los extractos derivados de ciertas plantas medicinales, de uso tradicional, son efectivos contra algunas especies de bacterias patógenas, resistentes a antibióticos, que colonizan la cavidad oral de los seres humanos. Además, comprueba que de $C$. spinosa produce compuestos con efecto inhibitorio sobre cepas de $S$. aureus resistentes a antibióticos.

Los extractos mostraron tener un efecto inhibitorio con diferencias significativas entre ellos. Los extractos de hojas y vainas tuvieron un efecto muy parecido, lo cual podría atribuirse a que tienen los mismos componentes fitoquímicos en dilución alcohólica, observándose medidas de halos mayores con los extractos de hojas, pero los porcentajes de inhibición de los extractos de vainas fueron mayores a los de hojas. Se observó que los porcentajes de inhibición de extractos de vainas y hojas fueron mayores que con los obtenidos a partir de semillas, observándose mayores diámetros de los halos. Muy probablemente esto se debe a que las semillas tienen una composición y estructura diferentes, de mayor resistencia, lo que no permite su trituración completa, por lo que el efecto de sus extractos sería más débil en comparación con los extractos de hojas y vainas. Para confirmar estas hipótesis sería necesario otro tipo de estudios analíticos como, por ejemplo, análisis cromatográficos.

El mayor efecto antibacteriano de extractos etanólicos de $C$. spinosa se observó en la cepa de $S$. aureus meticilino-resistente, demostrando medidas de halos mayores y porcentajes de inhibición mayores al comparar con la cepa de $S$. aureus penicilino-resistente con su respectivo tipo de extracto y concentración.

En el estudio de Rivera et al. ${ }^{28}$ sobre $S$. aureus, se observó que los halos fueron menores o iguales a $15 \mathrm{~mm}$, siendo la concentración de $100 \%$ la de mayor actividad antibacteriana con una media de $13,47 \mathrm{~mm}$, con un intervalo de 10 a $15 \mathrm{~mm}$ de halo inhibitorio, además el efecto de la eritromicina fue mayor a los extractos, lo cual es similar a lo obtenido en nuestro estudio, debido a que también se observó mayor diámetro de halo a la concentración de $100 \%$, pero se observó mayor efecto de los extractos de C. spinosa que el control positivo. También observaron que existieron altas diferencias significativas al comparar extractos y controles positivos ( $\mathrm{p}$ $<0,001)$, al igual que en nuestro estudio $(\mathrm{p}<0,001)$.

Algunos autores han reportado que compuestos de $C$. spinosa solubles en agua, etanol o acetona, poseen efecto antibacteriano particularmente contra cepas de $S$. aureus. Tal es el caso de: los gallotaninos y sus derivados hidrosolubles, además del ácido gálico, sin embargo, el que mayor efecto posee contra esta especie bacteriana es el ácido tánico. Estos componentes vegetales son de tipo fenólico con propiedades antibacterianas de amplio espectro contra bacterias grampositivas y gramnegativas como se demuestra en el estudio de Aguilar et al. ${ }^{10} \mathrm{y}$ el de He D et al. ${ }^{35}$

Por su parte Guevara et al. ${ }^{36}$ estudiaron el efecto de cocimientos tres biovariedades $C$. spinosa sobre cepas de $S$. aureus, 29 oxacilino-resistentes y 31 oxacilino-sensibles. Su preparación fue en base al método usado por la población a manera de infusión. Sus resultados mostraron actividad antibacteriana infusiones de $C$. spinosa sobre cepas sensibles y resistentes a oxacilina, pero la mayor actividad fue sobre cepas de $S$. aureus resistentes. Únicamente C. spinosa de Huarochirí no presentó efecto inhibitorio sobre dos cepas resistentes, mientras que sobre cepas sensibles si presentó halo inhibitorio. Las infusiones de C. spinosa de Huamanga y de Tarma son las que tuvieron mayor actividad comparada con la de Huarochirí, La especie de C. spinosa de Huamanga fue la que presentó mayor diámetro de inhibición sobre todas las cepas y su mayor efecto con una media de 26,14 $\pm 7,54 \mathrm{~mm}$ fue sobre cepas resistentes. A pesar de que la metodología usada en su estudio es diferente al nuestro, de igual manera se comprueba la actividad antibacteriana de C. spinosa sobre cepas resistentes, debido a que observamos mayor diámetro en los halos de los extractos que la de los controles positivos en la cepa de $S$. aureus meticilino-resistente. Hay que considerar que en su estudio, utilizaron únicamente cocimientos de la planta sin protocolo de preparación de extractos, ni metodología comprobada. ${ }^{36}$ Por el contrario, en nuestro estudio se puede destacar la preparación de un protocolo para obtención de extractos en base a evidencia científica, de manera que pudimos utilizarlos a diferentes concentraciones y a partir de los diferentes órganos de la planta estudiada.

Masoumian et al. ${ }^{37}$ y Abkhoo et al. ${ }^{38}$ ambos autores en sus estudios aplicaron extractos de diferentes especies vegetales, demostrando que los extractos alcohólicos, acuosos e hidroalcohólicos, son buenas opciones para eliminar $S$. aureus por sus efectos antibacterianos, debido a que evidenciaron una buena sensibilidad de estos extractos especialmente sobre cepas resistentes de S. aureus. Estos resultados se asemejan a los nuestros y apoyan la hipótesis de que las especies vegetales pueden combatir infecciones por $S$. aureus resistentes a antibióticos, sin generar resistencia ${ }^{24,39}$.

Según Shibata et al. ${ }^{40}$ en su estudio sobre galato de etilo purificado de una vaina seca de tara (Caesalpinia spinosa) demostró que intensificaba la susceptibilidad a $\beta$-lactámicos en cepas de Staphylococcus aureus resistentes a meticilina y sensibles a meticilina, además se probaron con cepas de $S$. aureus meticilino-resistentes (MRSA) y meticilino-sensibles (MSSA), el 90\% de los aislamientos analizados fueron inhibidos $(15,6 \mu \mathrm{g} / \mathrm{ml})$. A concentraciones inferiores a la MIC, los galatos de alquilo elevaron sinérgicamente la susceptibilidad de las cepas de $S$. aureus meticilino-resistentes y meticilino-sensibles a los antibióticos $\beta$-lactámicos, debido a que la longitud de la cadena de alquilo intensifica la susceptibilidad de manera específica con este tipo de antibióticos. Esto nos indica 
que puede también usarse con el antibiótico con el fin de evitar resistencia debido a su efecto sinérgico ${ }^{39,40,41}$.

Terán et al. ${ }^{42}$ Observaron que los aceites de tara tuvieron efecto inhibitorio sobre cepas resistentes, la CMI para S. aureus ATCC 25923, cepa sensible, se alcanza en la dilución 0,039\% del aceite esencial de frutos de tara, la CMB se alcanza en la dilución 0,156\% del aceite esencial, demostrando que las diluciones 0,039 y 0,078 generan un efecto bacteriostático sobre la cepa.

Como limitaciones del estudio se encuentran que es muy difícil controlar el grado de oxidación de los extractos con respecto al tiempo, además al realizar el proceso de obtención de extractos alcohólicos no se puede garantizar que se obtengan todos los componentes, sino solo los que tienen afinidad con el alcohol. También se podrían probar los extractos de $C$. spinosa sobre otras bacterias y a otras concentraciones, además de estudiar la Concentración Mínima Inhibitoria (CMI), que por limitaciones de disponibilidad de laboratorios, de equipos y de personal, no se llevaron a cabo. Otra limitación es que se estudió solamente una biodiversidad o variedad vegetal de C. spinosa, por lo que no se comparó con otras. Sin embargo, la limitación más importante de nuestro estudio fue que no se cuantificó la cantidad de extractos empleada en los ensayos y que los mismos no fueron liofilizados por condiciones del laboratorio durante el periodo de ejecución de la investigación.

No obstante, nuestro estudio aporta datos preliminares sobre el efecto antimicrobiano de los extractos de $C$. spinosa contra bacterias resistentes, que en la actualidad son limitados, como tratamiento alternativo de infecciones orales causadas por $S$. aureus. Por otro lado, los resultados obtenidos son importantes en relación con el control de la diseminación de la resistencia bacteriana a los antibióticos, originada en gran parte, por el uso desmedido y no controlado de los mismos.

Podemos concluir que todos los extractos de C. spinosa tuvieron efecto inhibitorio sobre el crecimiento de cepas de $S$. aureus, resistentes a antibióticos. Esto permite deducir la presencia de compuestos con actividad antimicrobiana en los diferentes órganos de esta planta. Se pudo observar que según la metodología en la que nos basamos, existe un patrón directamente proporcional en el que, a mayor concentración se obtiene un mayor efecto y halo inhibitorio. Se recomienda realizar más estudios con el fin de proporcionar información suficiente para la aplicación segura de extractos de esta especie vegetal como estrategia terapéutica clínica en odontología.

\section{Agradecimiento}

Se agradece a la Dra. Lennys Buela por su participación y apoyo en el estudio, así como al Dr. Luis Andrés Yarzábal por la revisión crítica y edición del presente manuscrito.

\section{Referencias bibliográficas}

1. Kon K, Rai M. Antibiotic Resistance: Mechanisms and New Antimicrobial Approaches. $1^{\text {a }}$ ed: Londres: Elsevier; 2016.
2. Khameneh B, Iranshahy M, Soheili V. et al. Review on plant antimicrobials: a mechanistic viewpoint. Antimicrob Resist Infect Control. [Internet] 2019 [citado 10 de mayo de 2020]; 8:118. DOI:10.1186/s13756-0190559-6. Disponible en: https://aricjournal.biomedcentral.com/articles/10.1186/s13756-019-0559-6\#citeas

3. Azuero A, Jaramillo C, San Martin D, D’Armas H. Análisis del efecto antimicrobiano de doce plantas medicinales de uso ancestral en Ecuador. Rev Cie UNEMI. [Internet] 2016 [citado 20 de mayo de 2020]; 9(20):11-18. DOI: 10.29076/issn.2528-7737. Disponible en: http://ojs. unemi.edu.ec/index.php/cienciaunemi/article/view/342

4. Montero M. Antimicrobial Resistance: What Should Dentists be Doing? Odovtos-Int J Dent Sc. [Internet] 2016 [citado 5 de junio de 2020]; 18 Special Clinical Issue: 10-14. DOI: 10.15517. Disponible en: https://www. medigraphic.com/pdfs/odovtos/ijd-2016/ijdE161a.pdf

5. Al-Snafi AE. Therapeutic properties of medicinal plants: a review of their antibacterial activity (Part 1). IJPT. [Internet] 2015 [citado 10 de Junio de 2020]; 6(3): 137158. Disponible en: https://cutt.ly/HbaZKT5

6. Huarino M, Ramos D. Efecto antibacteriano de Caesalpinia spinosa (Tara) sobre flora salival mixta. Odontol Sanmarquina. [Internet] 2013 [citado 10 de junio de 2020]; 16(1): 32-35. DOI: 10.15381/os.v16i1.5374 Disponible en: https://revistasinvestigacion.unmsm.edu. pe/index.php/odont/article/view/5374

7. Narváez A, Calvo A, Troya AM. Las poblaciones naturales de la tara (Caesalpinia spinosa) en el Ecuador: una aproximación al conocimiento de la diversidad genética y el contenido de taninos a través de estudios moleculares y bioquímicos. Serie Investigación y Sistematización No.7. Programa Regional ECOBONA-INTERCOOPERATION, Laboratorio de Biotecnología Vegetal Escuela de Ciencias Biológicas. Pontif Univ Cat del Ec PUCE. Quito. [Internet] 2009 [citado 22 de junio de 2020]. Disponible en: https://cutt.ly/BbaGerG

8. Aguilar A, Noratto G, Chambi F, Debaste F, Campos D. Potential of tara (Caesalpinia spinosa) gallotaninns and hydrolyzates as natural antibacterial compounds. Food Chem. [Internet] 2013 [Citado el 27 de junio de 2020]; 156:301-304. DOI: 10.1016/j.foodchem.2014.01.110. Disponible en: https://www.sciencedirect.com/science/ article/abs/pii/S0308814614001423

9. McCormack MG, Smith AJ, Akram AN, Jackson M, Robertson D, Edwards G. Staphylococcus aureus and the oral cavity: An overlooked source of carriage and infection? Am J Infect Control. [Internet] 2015 [citado 10 de junio de 2020]; 43: 35-7. Disponible en: https:// www.ncbi.nlm.nih.gov/pubmed/25564121

10. Gajdács M. The Continuing Threat of Methicillin-Resistant Staphylococcus aureus. Antibiotics (Basel). [Internet] 2019 [citado 10 de junio de 2020]; 8(2):52. DOI: 10.3390/antibiotics8020052. Disponible en: https:// www.ncbi.nlm.nih.gov/pmc/articles/PMC6627156/

11. Passariello C, Puttini M, Iebba V, Pera P, Gigola P. Influence of oral conditions on colonization by highly toxigenic Staphylococcus aureus strains. Oral Dis. 2012; 18(4):402-409 DOI: 10.1111/j.16010825.2011.01889.x. 
12. Kearney A, Kinnevey P, Shore A, Brennan G, Humphreys $\mathrm{H}$, Coleman DC. The oral cavity revealed as a significant reservoir of Staphylococcus aureus in an acute hospital by extensive patient, healthcare worker and environmental sampling. J Hosp Infect 2020; 105(3):389396. DOI: $10.1016 /$ j.jhin.2020.03.004.

13. Kim GY, Lee HC. Antimicrobial susceptibility and pathogenic genes of Staphylococcus aureus isolated from the oral cavity of patients with periodontitis. J Periodontal Implant Sci. [Internet] 2015 [citado 22 de junio de 2020]; 45(6):223-228. DOI: 10.5051/ jpis.2015.45.6.223 Disponible en: https://www.ncbi. nlm.nih.gov/pmc/articles/PMC4698949/

14. Loewen K, Schreiber Y, Kirlew M, Bocking N, Kelly L. Community-associated methicillin-resistant Staphylococcus aureus infection. Literature review and clinical update. Canad Fam Phys. [Internet] 2017 [citado 15 de junio de 2020]; 63(7):512-520. Disponible en: https:// www.cfp.ca/content/63/7/512

15. Cholán K, Zavaleta G, Saldaña J, Blas W. Efecto del extracto hidroalcohólico de Caesalpinia spinosa ( $\mathrm{Fa}$ baceae) sobre el crecimiento de Salmonella typhi y Escherichia coli. Arnaldoa [Internet]. 2019 [citado el 18 de junio de 2020]; 26(2):699-712. DOI: 10.22497/arnaldoa.262.26212 Disponible en: http:// www.scielo.org.pe/scielo.php?script=sci_arttext\&pi$\mathrm{d}=$ S2413-32992019000200012\&lng=es.

16. Cruz-Carrillo A, Rodríguez NN, Rodríguez CE. Evaluación in vitro del efecto antibacteriano de los extractos de Bidens pilosa, Lantana camara, Schinus molle y Silybum marianum. Rev UDCA Act. \& Div Cient [Internet]. 2010 [citado el 15 de agosto de 2020]; 13(2):117-124. Disponible en: http://www.scielo.org.co/scielo.php?pi$\mathrm{d}=$ S0123-42262010000200014\&script=sci_abstract\&t lng=es

17. Castillo-Mompié A, Pascual-Sanchez YM, CunhaNune LC, De la Paz C, Cañete F. Evaluación de la actividad antimicrobiana de extractos de hojas y semillas de Morinda citrifolia L. (noni). Rev cuba plantas med [Internet]. 2014 [citado el 15 de octubre de 2020]; 19(4): p. 374382. Disponible en: https://pesquisa.bvsalud.org/portal/ resource/pt/lil-750675

18. Pareja-Vásquez M, Pardo-Aldave K, Jurado-Teixeira B, Guillen A, Romero-Coasaca AC, Meneses-Rivadeneira L. Actividad antibacteriana del extracto etanólico de Caesalpina spinosa (Molina) Kuntze "tara" Fabaceae sobre bacterias de la biopelícula bucal. Diagnóstico [Internet]. 2020 Octubre 13 [citado el 2 de noviembre de 2020]; 58(1):5-11. DOI: 10.33734/diagnostico.v59i1.201 Disponible en: http://142.44.242.51/index.php/diagnostico/article/view/201

19. Mogollón García MV, Rodríguez Haro IM. Efecto del extracto hidroalcohólico y aceite esencial de hojas de Vallesia glabra sobre el crecimiento de Staphylococcus aureus meticilino resistente y Pseudomonas aeruginosa. Pueblo Cont. [Internet]. 2019 [citado el 2 de noviembre de 2020]; 30(1):299-306. DOI: 10.22497/PuebloCont.301.30128 Disponible en: http://journal.upao. edu.pe/PuebloContinente/article/view/1306

20. Gualtieri MJ, González MC, Contreras KP, Noguera MC, Uzcátegui EE, Villasmil S, et al. Evaluación de la actividad antimicrobiana de los extractos etanólicos de
Azadirachta indica. INHRR [Internet]. 2008 [citado el 11 de noviembre de 2020]; 39(2):12-16. Disponible en: http://ve.scielo.org/scielo.php?script=sci_arttext\&pi$\mathrm{d}=$ S0798-04772008000200003\&lng=es.

21. Corzo-Barragán DC. Evaluación de la actividad antimicrobiana del extracto etanólico. Rev Mex Cienc Farm [Internet]. 2012 [citado el 11 de noviembre de 2020]; 43(3): 81-86. Disponible en: http:// www.scielo.org. $\mathrm{mx} /$ scielo.php?script=sci_arttext\&pi$\mathrm{d}=$ S1870-01952012000300009

22. Rodríguez-Pava CN, Zarate-Sanabria AG, Sánchez-Leal L. Actividad antimicrobiana de cuatro variedades de plantas frente a patógenos de importancia clínica en Colombia. Nova [Internet]. 2017 [citado el 13 de noviembre de 2020]; 15(27):19-129. DOI: 10.22490/24629448.1963 Disponible en: https://revistas.unicolmayor.edu.co/index.php/nova/article/view/582

23. Montenegro A, Ramos D. Actividad antibacteriana de Caesalpinia spinosa (tara) sobre Porphyromonas gingivalis. Odontol Sanmarquina [Internet] 2016 [citado 5 de Julio de 2020]; 19(1):7-11. DOI: 10.15381/05. v19i1.12175 Disponible en: https://revistasinvestigacion. unmsm.edu.pe/index.php/odont/article/view/12175

24. Chatterjee SK, Bhattacharjee I, Chandra G. Bactericidal Activities of Some Common Herbs in India. Pharm Biol [Internet]. 2007 [citado el 13 de noviembre de 2020]; 45(5):350-354. DOI: 10.1080/13880200701212940 Disponible en: https://www.tandfonline.com/doi/ full/10.1080/13880200701212940

25. Callohuari R, Sandoval Vegas M, Huamán Gutiérrez O. Efecto gastroprotector y capacidad antioxidante del extracto acuoso de las vainas de Caesalpinia spinosa 'tara', en animales de experimentación. An Fac med [Internet]. 2017 [citado el 11 de noviembre de 2020]; 78(1):616. DOI: 10.15381/anales.v78i1.13023. Disponible en: http://www.scielo.org.pe/scielo.php?script=sci_arttext\&pid=S1025-55832017000100010

26. Bornaz Acosta JG, Bornaz Arenas VL, Bornaz Arenas MC. Efecto in vitro de la solución de Caesalpinia espinosa (TARA) AL 60\%, e hidróxido de calcio y gluconato de clorexhidina al $2 \%$ en el halo inhibitorio microbiano de Enterococcus faecalis. Cienc Des. [Internet]. 2014 [citado el 11 de noviembre de 2020]; 17:13-16. DOI: $10.33326 / 26176033.2014 .18 .426$. Disponible en: http://revistas.unjbg.edu.pe/index.php/cyd/article/ view/426

27. Cuervo Salcedo D, Vanegas Campos J, Corzo D, Correa F. Evaluación de la capacidad bactericida de extractos vegetales de distinta polaridad de Drimys granadensis. Rev peru biol [Internet]. 2019 [citado el 12 de noviembre de 2020]; 26(1):135-142. DOI: 10.15381/rpb.v26i1.15917 Disponible en: http:// www.scielo.org.pe/scielo.php?script=sci_abstract\&pi$\mathrm{d}=$ S1727-99332019000100016\&lng=es\&nrm=iso

28. Rivera ML, Llaque MR, Polo JA. Efecto antimicrobiano del extracto etanólico de Caesalpinia spinosa "tara" sobre Staphylococcus aureus ATCC 25923 comparado con eritromicina. Rev Med Vall. [Internet]. 2020 [citado el 18 de junio de 2020]; 9(1):52-5. DOI: 10.18050/ revistamedicavallejiana.v9i1.2504 Disponible en: http:// revistas.ucv.edu.pe/index.php/REVISTAMEDICAVALLEJIANA/article/view/2504 
29. Zárate MA. Efecto in vitro antibacteriano del extracto acuoso de Caesalpinia spinosa "Tara" sobre cepas de Streptococcus pyogenes y escherichia coli aisladas de pacientes del Hospital Regional Docente de Trujillo en el año 2014. Pueblo cont. [Internet] 2015 [citado el 5 de Julio de 2020]; 26(1): 15-23 Disponible en: http://journal.upao.edu.pe/PuebloContinente/article/view/284

30. Díaz M, Lugo Y, Fonte L, Castro I, López O, Montejo L. Evaluación de la actividad antimicrobiana de extractos frescos de hojas de Morus alba L. Past y forr [Internet]. 2017 [citado el 12 de noviembre de 2020]; 40(1):43-48. Disponible en: http://scielo.sld.cu/scielo.php?script=sci_ arttext\&pid=S0864-03942017000100006\&lng=es\&n$\mathrm{rm}=\mathrm{iso}$.

31. Alvarado SL, Herrera P, Enoki-Miñano E, Ruiz-Barrueto M, Millones PA. Efecto antibacteriano in vitro del extracto etanólico de Prosopis pallida sobre Enterococcus faecalis ATCC 29212. Rev Cuba Med Trop [Internet]. 2018 [citado 20 de julio de 2020]; 70(2):1-12. Disponible en: http://revmedtropical.sld.cu/index.php/medtro$\mathrm{pical} /$ article/view/287

32. De O. Ribeiro IC, Mariano GA, Careli RT, Morais-Costa F, De Sant'Anna FM, Pinto M, et al. Plants of the Cerrado with antimicrobial effects against Staphylococcus spp. and Escherichia coli from cattle. BMC Vet Res [Internet]. 2018 [citado el 13 de noviembre de 2020]; 14(1):1-10. DOI: 10.1186/s12917-018-1351-1 Disponible en: https:/www.ncbi.nlm.nih.gov/pmc/articles/ PMC5791213/

33. Din WM, Jin KT, Ramli R, Mohd T, Khaithir N, Wiart C. Antibacterial Effects of Ellagitannins from Acalypha wilkesiana var. macafeana hort.: Surface Morphology Analysis with Environmental Scanning Electron Microcopy and Synergy with Antibiotics. Phytother Res [Internet]. 2013 [citado el 11 de noviembre de 2020]; 27:1313-1320. DOI: 10.1002/ptr.4876. Disponible en: https://onlinelibrary.wiley.com/doi/abs/10.1002/ ptr.4876

34. Vivot E, Massa R, Cruañes M, Muñoz DD, Ferraro G, Gutkind G, et al. Actividad Antimicrobiana In Vitro de Seis Especies Autóctonas de la Flora de Entre Ríos (Argentina). Lat Am J Pharm [Internet]. 2007[citado el 10 de noviembre de 2020]; 26(4):563-6. Disponible en: http://www.latamjpharm.org/resumenes/26/4/LAJOP_26_4_2_3.pdf

35. He D, Li Y, Tang H, Ma R, Li X, Wang L. Six new cassane diterpenes from the twigs and leaves of Tara (Caesalpinia spinosa Kuntze). Fitoterapia [Internet] 2015 [citado 4 de Julio de 2020]; 105:273-277. Disponible en: https://www.sciencedirect.com/science/article/abs/pii/ S0367326X15300551
36. Guevara JM, Guevara JC, Guevara JM, Béjar V, Huamán A, Valencia E, et al. Evaluación del cocimiento de diferentes biovariedades de Caesalpinia spinosa (tara) frente a cepas de Staphylococcus aureus sensibles y resistentes a oxacilina. An Fac med., Univ. nac. mayor San Marcos [Internet] 2014 [citado 5 de Julio de 2020]; 75(2):177180. DOI: 10.15381/anales.v75i2.8379 Disponible en: http://www.scielo.org.pe/scielo.php?script=sci_arttext\&pid=S1025-55832014000200015\&lng=es.

37. Masoumian M, Zandi M. Antimicrobial Activity of Some Medicinal Plant Extracts against Multidrug Resistant Bacteria. Zahedan. J Res Med Sci. [Internet]. 2017 [citado el 7 de Julio de 2020]; 19(11):e10080. DOI: 10.5812/zjrms.10080. Disponible en: http://zjrms.com/ articles/10080.html

38. Abkhoo J, Jahani S. Efectos antibacterianos de extractos acuosos y etanólicos de plantas medicinales contra cepas patógena. Int J Infect. [Internet] 2017 [citado el 3 de Julio de 2020]; 4(2): e42624. DOI: 10.5812/iji.42624. Disponible en: http://intjinfection.com/articles/12837. html

39. Wood S. Methicillin-Resistant Staphylococcus aureus. En: Bornstein J. Vulvar Disease. $1^{\text {a }}$ ed. Suiza. Springer, Cham [Internet]; 2019 [citado el 4 de Julio de 2020]. DOI: 443.webvpn.fjmu.edu.cn/10.1007/978-3-31961621-6_46. Disponible en:

40. Shibata H, Kondo K, Katsuyama R, Kawazoe K, Sato Y, Murakami K, et al. Alkyl Gallates, Intensifiers of $\beta$-Lactam Susceptibility in Methicillin-Resistant Staphylococcus aureus. Antimicrob. Agents Chemother. [Internet] 2005 [citado 4 de Julio de 2020]; 49(2):549-555. DOI: 10.1128/AAC.49.2.549-555.2005 Disponible en: https://aac.asm.org/content/49/2/549.short

41. Qin R, Xiao K, Li B, Jiang W, Peng W, Zheng J, et al. The Combination of Catechin and Epicatechin Gallate from Fructus Crataegi Potentiates $\beta$-Lactam Antibiotics Against Methicillin-Resistant Staphylococcus aureus (MRSA) in Vitro and in Vivo. Int J Mol Sci. [Internet] 2013 [citado 4 de Julio de 2020]; 14(1):1802-1821. DOI: $10.3390 /$ ijms14011802. Disponible en: https:// www.mdpi.com/1422-0067/14/1/1802

42. Terán YA, Guillermo J, Gómez KM, Reyna LA, Avila EF. Efecto in vitro del aceite esencial de los frutos de Caesalpinia spinosa (molina) Kuntze, tara sobre la viabilidad de cultivos de Staphylococcus aureus meticilino resistente. Pueblo cont. [Internet] 2015 [citado 4 de Julio de 2020]; 26(1):75-87. Disponible en: http://200.62.226.189/ PuebloContinente/article/view/289/257 